\title{
Duration of the Electromyographic Silent Period Following the Jaw-Jerk Reflex in Human Subjects
}

\author{
David G. Manamara, Patrick F. Grane, Willard D. McGall, Jr., and Major M. Ash, Jr. \\ Department of Occlusion, Dental Research Institute, \\ School of Dentistry, University of Michigan, Ann Arbor, Michigan 48109, USA
}

During voluntary jaw clenching, a sharp tap to the menton of the mandible resulted in a transitory silent period (pause) in the electromyographic activity of the masseter and anterior temporalis muscles. Factors that could infuence the duration of the silent period were studied, including direction and magnitude of the stimulus applied by the operator, the amount of muscular effort exerted by the subjects, and varying occlusal vertical dimensions. Decreased isometric muscle force resulted in statistically significant increases in silent period durations.

\section{J Dent Res 56(6):660-664 June 1977.}

The electromyographic (EMG) silent period phenomenon was first reported for human subjects by Hoffmann, ${ }^{1}$ and was explained as central refractoriness of the motor neurons due to a superimposed reflex twitch on the contraction of a muscle. The jaw-jerk is a myotactic reflex that is activated by sudden stretching of the muscle spindles in the jaw-closing muscles. $^{2}$ Afferent nerve fibers from these muscle spindles run in the motor root of the trigeminal nerve, whereas the fibers of the Golgi tendon organs run together with other $\mathrm{V}$ nerve afferents in the sensory root. Surgical cutting of the sensory root for patients with trigeminal neuralgia will eliminate the inhibitory polysynaptic reflexes including the effects of the tensionsensitive Golgi organs. ${ }^{3}$ This results in the persistence of the jaw-jerk reflex; however, the EMG silent period that followed had a signifi-

This investigation was supported by USPHS Grant DE-02731.

Received for publication April 23, 1976.

Accepted for publication July 9,1976

* Grass Instrument Co., Quincy, Ma.

$\dagger$ Beckman Instrument Inc., I1. Ma.

Grass Model 78, Grass Instrument Co., Quincy,

$\S$ Hewlett Packard Model 3955, Mt. View, Ca.

\# Model HI-5 American Aerospace Controls Inc., New York, NY. cantly shorter duration or was completely eliminated in the temporal and masseter muscles of the operated side. Since an increase in duration of the masseteric silent period is considered a useful diagnostic measurement for patients with temporomandibular joint (TMJ) pain-dysfunction syndrome, ${ }^{4}$ the effects of operator and subject input variables on the EMG silent period duration should be determined. ${ }^{5}$

This study examines the effects of varying the type of mechanical stimulation, muscle tension, and increase in occlusal vertical dimension on the EMG silent period duration of the temporal and masseter muscles in healthy, young human subjects with complete dentitions.

\section{Materials and Methods}

EMG TEChNiques.-Disk surface electrodes* were used in preference to needle or hook electrodes to avoid any painful influences. Bipolar leads, $3 \mathrm{~cm}$ apart, were placed bilaterally on median locations for the superficial masseter, anterior temporalis, and anterior digastric muscles. A standardized technique enabled reproducible placement of electrodes for each subject. The area of placement was scrubbed with alcohol and then conductive electrode cream was applied between the electrodes and the skin to reduce the contact impedance. Adhesive collars $\dagger$ were used to secure the electrodes and prevent movement artifacts. A polygraph $\neq$ console, modified for electromyography, amplified the muscle action potentials for recording on analog magnetic tape by a seven-channel tape recorder $\$$ at $30 \mathrm{in} / \mathrm{sec}$. Replay at four times reduction of speed, $7 \mathrm{r} / 2$ ips, into the ink-writing oscillograph enabled measurement of the silent period durations either by hand or by a special computer peripheral. ${ }^{6}$ Five channels were used to record EMG muscle activity, the sixth channel for alterations of jaw-position monitored by a Halleffect generator\# and magnet attached to op- 
posing central incisors, ${ }^{7}$ and the seventh channel for bite force.

Statistical analyses were implemented using an analysis of variance program for nested and fully crossed designs with equal cell size, available at the University of Michigan timesharing computer system. Three experiments were done. Experiment 1 was designed to examine the influence of the strength of the jaw-tap stimulus on the EMG silent period duration (SPD). Each subject was instructed to clench his jaws together while six gentle (2 $\mathrm{kg}$ approximately), hard ( $3 \mathrm{~kg}$ approximately), and painful (more than $4 \mathrm{~kg}$ ) mechanical taps were delivered with a reflex mallet in a downward direction to the menton. A force gauge placed on the menton monitored the load delivered to the chin.

Experiment 2 investigated the influence of alterations in the voluntary muscle tension on the SPD. Each subject clenched on a force transducer placed between his right premolars and voluntarily maintained a constant 5-, 10 -, or $15-\mathrm{kg}$ load on the transducer with the visual aid of a meter. Six hard jaw-taps were delivered at each load.

Experiment 3 determined the effect of increases in the occlusal dimension on the SPD. Each subject exerted a constant 5-kg clench on the transducer at 10,20 , or $30 \mathrm{~mm}$ of vertical dimension between the right premolars. Six hard jaw-taps were delivered at each vertical dimension.

In experiments 2 and 3 , jaw-taps were delivered in a downward direction to the menton and caused a momentary decrease of force recorded between the premolars; hence these were termed jaw-jerks (unload). Jaw-taps delivered in an upward direction to the menton resulted in a momentary increase of force between the teeth and hence these were termed jaw-jerks (load). Six taps of each type of jawtap were delivered for each of the different test procedures. Eighteen healthy, young adults ( 20 to 27 years old) with no signs of functional TMJ or muscle disturbances were studied. Nine of the subjects, seven females and two males, with no previous experience of jaw-jerk reflex stimulation were studied in experiment 1, whereas a separate group of nine, again seven females and two males, were studied in experiments 2 and 3 .

\section{Results}

Different Muscles.--There was no significant difference $(F=1.9$ on 2 and $16 d f)$ in the EMG SPDs among the different muscles examined (Table 1). However, the painful tap in excess of $4 \mathrm{~kg}$ often resulted in the two distinct silent periods.

DiRection of Stimulus.-Jaw-taps delivered in a downward direction to the menton resulted in a rapid momentary decrease of force which is followed by a more definite gradual lessening of clenching force between the right premolars (Fig 1). Jaw-taps in an upward direction resulted in a rapid momentary increase of force between the teeth followed also by an overall decrease in clenching force resulting from the silent period in muscle activity (Fig 2). Jaw movement was not observed during either procedure.

BITE ForCE.-The differences between the EMG silent period durations are significant $(F=8.3$ on 2 and $16 d f ; P<0.01)$ for the three voluntary clenching efforts at 5,10 , and $15 \mathrm{~kg}$, respectively (Table 2 ). In addition, there was a significant difference between the SPD values for the muscles examined $(F=$ 12.4 on 3 and $24 d f ; P<0.001)$ and a significant force-muscle interaction $(F=3.3$ on 6

TABLE 1

Cell Means (msec) of the EMG SPDs Following Jaw-Tap Stimulation Downward to the Menton for Nine Healthy Subjects

$(S E \pm 1.17 \mathrm{msec})$

\begin{tabular}{lccc}
\hline & \multicolumn{3}{c}{ Jaw-Taps } \\
\cline { 2 - 4 } $\begin{array}{c}\text { Muscles } \\
\text { Examined }\end{array}$ & $\begin{array}{c}\text { Gard } \\
(2 \mathrm{~kg} \text { Force } \\
\text { Approximately })\end{array}$ & $\begin{array}{c}\text { Painful } \\
\text { (3 kg Force } \\
\text { Approximately) }\end{array}$ & $\begin{array}{c}\text { (4 kg Force } \\
\text { Approximately })\end{array}$ \\
\hline Right temporalis & 15.61 & 17.41 & 17.26 \\
Left temporalis & 14.84 & 16.72 & 17.07 \\
Right masseter & 17.74 & 18.68 & 17.81 \\
Left masseter & 16.42 & 17.92 & 19.19 \\
\hline
\end{tabular}

Note: $S E$, standard error of the mean. 


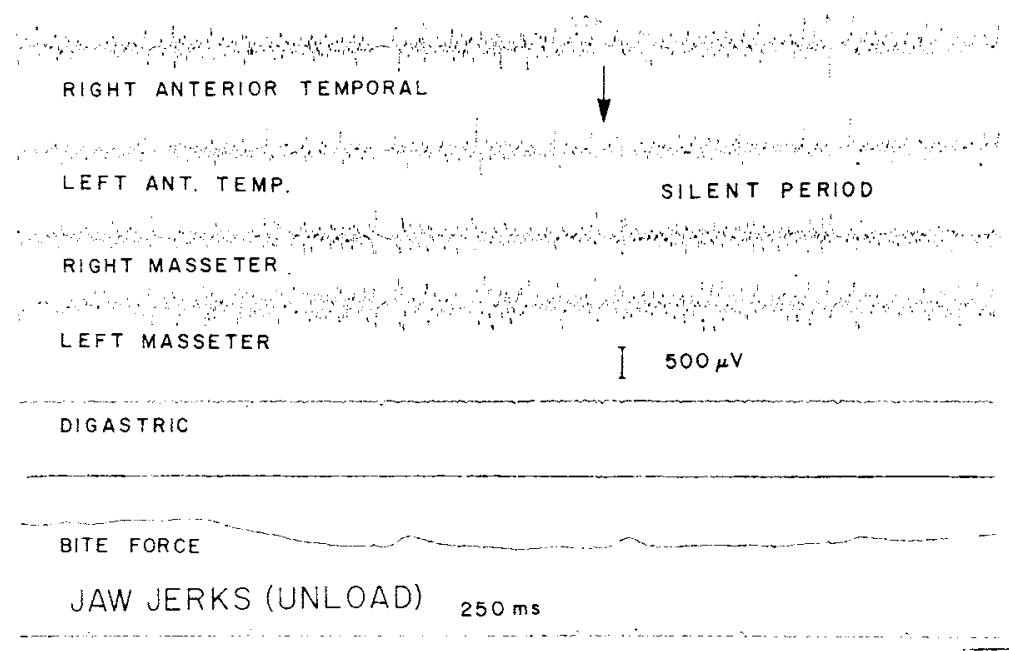

FIG 1.-Typical raw data for jaw-jerk (unload). These tracings were recorded on replay at a four-to-one speed reduction in analog tape recorder. Unlabeled trace represents jaw position, which did not change. Calibration marks for both time and EMG amplitude are given in the figure.

and $16 \mathrm{df} ; \mathrm{P}<0.01)$. The interaction between force and type of jaw-tap $(F<1)$ was not significant.

Vertical Dimension.-At the different vertical dimensions of 10,20 , and $30 \mathrm{~mm}$ opening from intercuspal position, there was no significant difference $(F<1)$ between the durations of the EMG silent periods (Table 3 ). However, again the difference between SPD values of the right and left masseter and anterior temporalis muscles was statistically sig- nificant $(F=22.2$ on 3 and $24 d f ; P<0.001)$. The interaction between vertical dimension and type of jaw-tap $(F<1)$ was not significant.

\section{Discussion}

The method of eliciting the jaw-jerk reflex does not significantly alter the resultant EMG SPD. These results agree with another study where numerous directions and differing natures of mandibular taps had no statisical

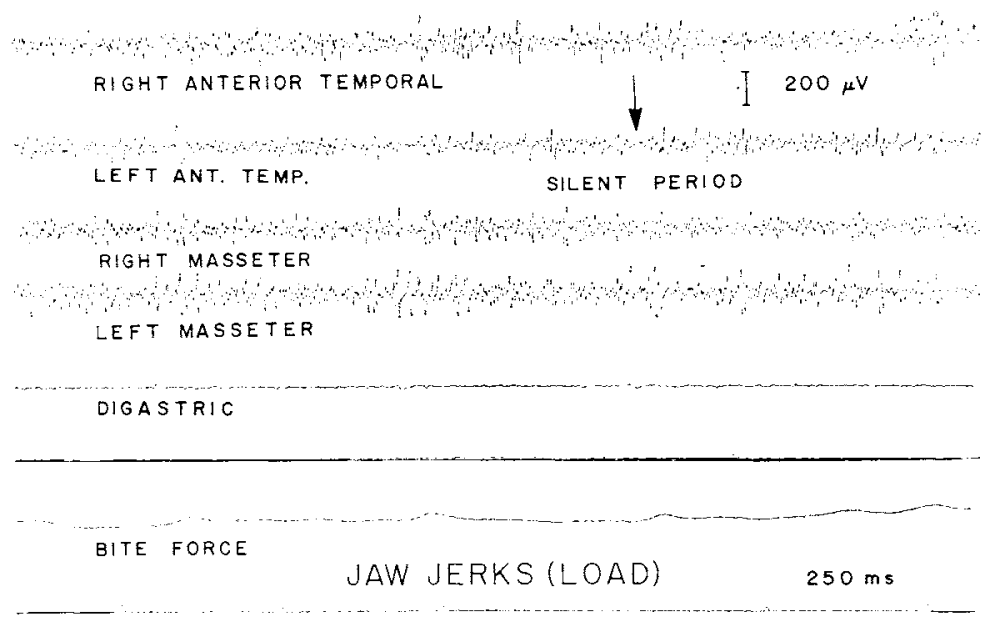

Fig 2.-Typical raw data for jaw-jerk (load). Caption of Figure 1 also applies to this figure. 


\section{TABLE 2}

Cell Means (msec) of the EMG SPDs FollowING JAW-TAP DownWard (UNLOAD) and UpWard (LOAD) to The Menton, at Different Biting Forces Between the Right Premolars $(S E \pm 2.63 \mathrm{msec})$

\begin{tabular}{lccc}
\hline \multirow{2}{*}{$\begin{array}{c}\text { Muscles } \\
\text { Examined }\end{array}$} & \multicolumn{3}{c}{ Biting Forces } \\
\cline { 2 - 4 } & $\mathbf{1 5 \mathrm { kg }}$ & $10 \mathrm{~kg}$ & $\mathbf{5 ~ \mathbf { ~ k g }}$ \\
\hline During downward (unload) jaw-taps \\
$\quad$ Right temporalis & 20.24 & 26.36 & 31.19 \\
Left temporalis & 24.23 & 28.11 & 34.28 \\
Right masseter & 16.92 & 21.44 & 25.89 \\
Left masseter & 17.92 & 20.61 & 24.75 \\
During upward (load) jaw-taps & & \\
$\quad$ Right temporalis & 18.50 & 23.16 & 30.75 \\
Left temporalis & 22.28 & 27.64 & 32.25 \\
Right masseter & 16.69 & 19.81 & 22.55 \\
Left masseter & 14.97 & 17.72 & 20.25 \\
\hline
\end{tabular}

Note: $S E$, standard error of the mean.

significance on the latency-inhibition behavior of the contracting masticatory muscles. ${ }^{8}$ Furthermore, electrical stimulation of the motor nerve of another human muscle has shown that once the threshold voltage is reached, progressively increasing the shock does not alter the duration of the silent period. ${ }^{9}$

The decrease of SPD with increasing amounts of clenching force tends to reinforce the role of Golgi tendon organs and periodontal receptors involved in inhibition of masticatory muscles. ${ }^{10}$ In addition, increasing the level of masseter muscle activity is shown to decrease the duration of inhibition produced by innocuous and noxious stimulation of facial and intraoral regions. ${ }^{11}$ These results differ from a previous report ${ }^{5}$ but agrec with results from other muscles in man that indicate that the duration of silent period depends on the level of the initial muscle activity. ${ }^{12}$ The highly significant force-muscle interaction of this study, together with the lack of variance in SPD with increases in vertical dimension, adds support to the suggestion that during isometric contraction tension receptors are more important in the peripheral feedback operating a tension-servo, rather than a length-servo mechanism. ${ }^{13}$

Patients with TMJ pain-dysfunction generally have only one half to two thirds the maximal vertical clenching force produced by normal subjects. ${ }^{14}$ Therefore, the possibility exists that the increase in SPD recorded for patients with TMJ pain-dysfunction is related
TABLE 3

Cell Means (msec) of the EMG SPDs

Following JAW-TAP DOWNWARD (UNLOAD) AND UPWARD (LOAD) TO THE MENTON, AT Different Occlusal Vertical Dimensions Between the Right Premolars ( $S E \pm 0.83 \mathrm{msec}$ )

\begin{tabular}{lccc}
\hline & \multicolumn{3}{c}{ Vertical Dimensions } \\
\cline { 2 - 4 } Examined & $10 \mathrm{~mm}$ & $20 \mathrm{~mm}$ & $30 \mathrm{~mm}$ \\
\hline During downward (unload) & jaw-taps & \\
Right temporalis & 31.19 & 27.19 & 29.66 \\
Left temporalis & 34.28 & 34.25 & 34.44 \\
Right masseter & 25.89 & 27.25 & 27.22 \\
Left masseter & 24.75 & 25.39 & 29.55 \\
During upward (load) jaw-taps & & \\
Right temporalis & 30.75 & 27.94 & 28.14 \\
Left temporalis & 32.25 & 31.17 & 30.28 \\
Right masseter & 22.56 & 22.61 & 23.06 \\
Left masseter & 20.25 & 21.31 & 24.78 \\
\hline
\end{tabular}

Note: $S E$, standard error of the mean.

to the loss of clenching force and the painful limitation. However, animal experiments have shown that mechanoreceptors in the TMJ capsule discharged spontaneously and provided important reflex contributions to mandibular muscle activity, which may participate in the development and regulation of interocclusal forces. ${ }^{15}$ Therefore, the prolongation of SPD in TMJ pain-dysfunction may be associated with polysynaptic reflex influences from the joint capsule on the degree of muscle activity. The EMG silent period following the jaw-jerk reflex can be initiated by several mechanisms, but the duration is apparently related to contractile events, especially the sensory contributions from the muscle spindle, tendon organ, the periodontal ligament receptors, and TMJ capsule receptors.

\section{Conclusions}

The duration of the EMG silent period in the masseter and temporalis muscles of man depends on the level of initial isometric muscle activity. Thus, if the EMG SPD following jawtap stimulation is used as a laboratory test for patients with functional disturbances of the masticatory system, the bite load should be recorded.

The authors thank Norma Staples for her assistance in patient management and EMG recordings, and Dr. C. J. Kowalski for his guidance in the statistical analyses. 


\section{References}

1. Hoffmann, P.: Demonstration eines hemmungsreflexes in menschilichen ruckenmark, $Z$ Biol 70:515-524, 1920.

2. MaIntyre, A.K.: Afferent Limb of the Myotactic Reflex Arc, Nature (Lond) 168: 168-169, 1951.

3. von Struppler, A.; Kesset, F.K.; and WEIDENBACH, W.: Elektrophysiologische Untersuchungen an de-afferentierten menschlichen muskeln, Med Monatsschr 14:25-26, 1960.

4. Bessette, R.; Bishop, B.; and Mohl, N.: Duration of Masseteric Silent Period in $\mathrm{Pa}-$ tients with TMJ Syndrome, I Appl Physiol 30:864-869, 1971.

5. Bessette, R.; Duda, L.; Mohr, N.D.; and BIs HOP, B.: Effect of Biting Force on Duration of the Masseteric Silent Period, J Dent Res 52:426-430, 1973.

6. Altug, S.S.; Childress, C.T., JR.; DeMUND, S.M.; MaGall, W.D., JR.; and Ash, M.M., JR.: An Interactive Computer Peripheral to Measure the Electromyographic Silent Period, IEEE Trans. on Biomed. Engr., March 1975, accepted for publication.

7. MCCALL, W.D., JR.; Bailey, J.O., JR.; and Ast, M.M., JR.: A Quantitative Measure of TMJ Dysfunction: Phase Plane Modelling of Jaw Motion in Man, Arch Oral Biol, accepted for publication.
8. Gillings, B.R.D.: Inhibition of Masticatory Muscle Activity After Stimulation, J Dent Res 53:141, 1974.

9. Merton, P.A.: The Silent Period in a Muscle of the Human Hand, $J$ Physiol (Lond) 114:183-198, 1951.

10. Beaudreau, D.E.; Daugherty, W.F., Jr.; and Masland, W.S.: Two types of Motor Pause in Masticatory Muscles, Am J Physiol 216:16-21, 1969.

11. Yu, S.K.; Schmitt, A.; and Sessle, B.J.: Inhibitory Effects of Jaw Muscle Activity of Innocuous and Noxious Stimulation of $\mathrm{Fa}$ cial and Intraoral Sites in Man, Arch Oral Biol 18:861-870, 1973.

12. Agarwal, G.C., and Gotruieb, G.L.: The Muscle Silent Period and Reciprocal Inhibition in Man, $J$ Neurol Neurosurg Psychiatry 35:72-76, 1972.

13. Simpson, J.A.: Gontrol of Muscle in Health and Disease, in ANDrew, B.L., and Thompson, D.C. (eds): Control and Innervation of Skeletal Muscle, Dundee, Publisher, 1966, pp 171-181.

14. Molis, C.: Vertical Isometric Muscle Forces of the Mandible: A Comparative Study of Subjects With and Without Manifest Mandibular Pain Dysfunction Syndrome, Acta Odontol Scand 30:485-499, 1972.

15. Klineberg, I.: Structure and Function of Temporomandibular Joint Innervation, $A n n$ $R$ Coll Surg Engl 49:268-288, 1971. 